\title{
Retrospective Analysis of 170 Patients Followed up with Herpes Zoster and Postherpetic Neuralgia in Nothern Cyprus
}

\author{
${\text { Dua } \text { Cebeci }^{1 *} \text { (D) Seide Karasel }}^{2}$ (D) \\ ${ }^{1}$ Department of Dermatology and Venerology, Famagusta State Hospital, Famagusta, Cyprus; ${ }^{2}$ Department of Physical \\ Medicine and Rehabilitation, Famagusta State Hospital, Famagusta, Cyprus
}

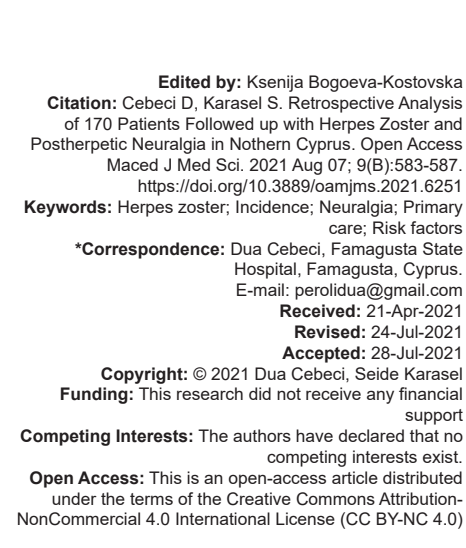

Introduction

Herpes zoster $(\mathrm{HZ})$, is a viral disease characterized by a painful skin rash with blisters in a localized area. It is a viral disease caused by the reactivation of the chickenpox-zoster virus that is dormant in the sensory ganglia or dorsal root ganglia of the cranial nerve after chickenpox infection [1]. It is a common disease, with a reported incidence varying from 2.2 to $3.4 / 1000$ patients/year [2]. While Varicella-zoster is more common in children as form as chickenpox, herpes zoster occurs in adults or the elderly [1].

The most common neurological complications associated with $\mathrm{HZ}$ is postherpetic neuralgia (PHN), defined as pain at least for 90 days after the onset of rash. $\mathrm{PHN}$ is characterized by persistent spontaneous sharp or paroxysmal burning sensation and neuropathic pain, including hyperesthesia, affecting the patient's quality of life. PHN is estimated to affect $10-20 \%$ of all patients with $\mathrm{HZ}$ over the age of 50 and $30 \%$ of those aged 80 years [3].
Diagnosis of $\mathrm{PHN}$ requires consideration of known risk factors, including advanced age, severe prodromal pain, severe rash, and $\mathrm{HZ}$ location on the trigeminal dermatomes or the brachial plexus [4].

PHN patients have a poor quality of life and difficulty in daily living activities. Approaches to managing postherpetic neuralgia include preventing herpes zoster by vaccination and/or antiviral therapy and administering specific drugs to treat pain. Moreover, treatment of PHN due to $\mathrm{HZ}$ is particularly difficult in the elderly population [5].

Tricyclic antidepressants, gabapentin and pregabalin, and topical lidocaine $5 \%$ tape are categorized as first-line treatments for $\mathrm{PHN}$ in guidelines published by the American Academy of Neurology (2004) [6]. Opioids, tramadol, capsaicin cream, and $8 \%$ capsaicin patch are generally considered second or third-line treatments due to safety and/or efficacy disadvantages compared to first-line treatments [7].

In this study, we retrospectively determined the incidence of $\mathrm{HZ}$ and $\mathrm{PHN}$ in patients enrolled in the general practice research database and analyzed risk indicators for $\mathrm{PHN}$. 


\section{Methods}

\section{Patients and setting}

Data were collected from the General Practice Research Database. All HZ patients diagnosed between October 30, 2018, and October 31, 2020, were identified by searching the database for the ICPC code B0.09, B0.01 (HZ), and for free text ("zoster"). Patients admitted to the hospital and diagnosed with these ICD codes were included in the study. During the study, two authors, one of whom was a dermatologist and the other a physiatrist (took part in data collection and follow-up of patients who developed $\mathrm{PHN}$ ), made general practices and examined the full-text medical records of the selected patients. The duration of pain was recorded for each $\mathrm{HZ}$ patient. In this study, PHN was defined as any pain that persists for at least 3 months after the diagnosis of $\mathrm{HZ}$. Patients age, gender, localization, presence of prodrome pain, time between symptom and presentation, comorbidity pain severity, medication for $\mathrm{HZ}$ (systemic local) were questioned. Relevant comorbidity included diabetes mellitus (DM), Hypertension, cardiovascular disease, $\mathrm{HIV}$, and Malignancy, at the time of $\mathrm{HZ}$ diagnosis. Topical or systemic antiviral treatments were applied according to the risk status of the patients and the severity and dermatomal location of the lesions.

\section{Statistical analysis}

All analyzes were performed on SPSS v15 (SPSS Inc., Chicago, IL, USA). Shapiro-Wilk test was used to determine whether variables are normally distributed. Number, percentage, mean, standard deviation (SD), median, minimum and maximum values were used in the evaluation of descriptive data. Categorical data were compared using the Chi-square test and continuous data were compared with Student's t or Mann-Whitney $U$ tests according to the distribution. Univariate and Multivariate Logistic Regression Analysis was performed to determine risk factors for postherpetic neuralgia and sequelae after shingles infection.

\section{Results}

A search of the database resulted in 6233 patients, 170 of whom were diagnosed as having $\mathrm{HZ}$, equally distributed over the 2-year period. There were 170 patients, 76 (44.7\%) male, 94 (55.3\%) female, who had $\mathrm{HZ}$ infection in the study group. The ages of the patients ranged from 5 to 88 years, (the mean \pm SD was $50.8 \pm 19.2)$ years, and $2.4 \%(n=4)$ of the patients were under 18 years old. The lesions were vesicles, papules, pustules, on erythematous bases, and crusts or present in various combinations (Figure 1).

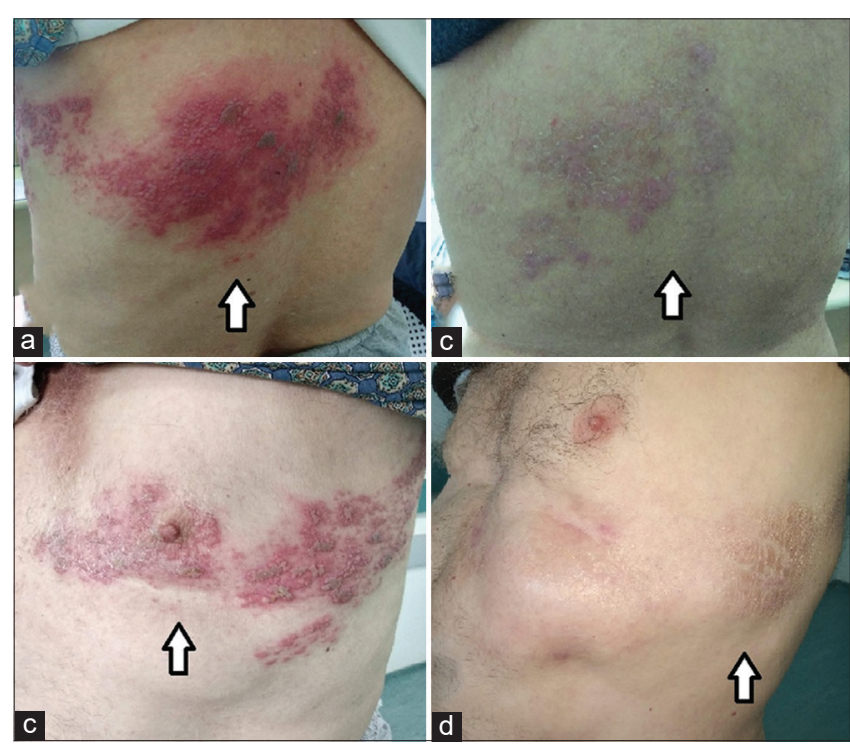

Figure 1: (a and c) Left image shows typical presentation of acute herpes zoster in the thoracal region (2. Day )in 54-years-old male patient. ( $b$ and $d$ ) Right image illustrates typical presentation of postherpetic neuralgia, with pain persisting $>2$ months after the acute rash, which may have completely disappeared or left scant scarring

The mean \pm SD of the patients for $\mathrm{HZ}$ infection was $5.8 \pm 5.5$ days. While medical treatment was applied to $82.9 \%(n=141)$ of the patients, topical treatment was applied to $17.1 \%(n=29)$ of them. The frequency of patients with any comorbidity in the study group was $55.3 \%(n=94)$. The incidence of prodromal findings in patients was $68.8 \%(n=117)$, and the incidence of postherpetic neuralgia was $21.8 \%(n=37)$. The frequency of post-infective sequelae (atrophy, hypo/ hyperpigmentation) among the patients was found to be $26.5 \%(n=45)$ (Figure 2$)$ (Table 1$)$.

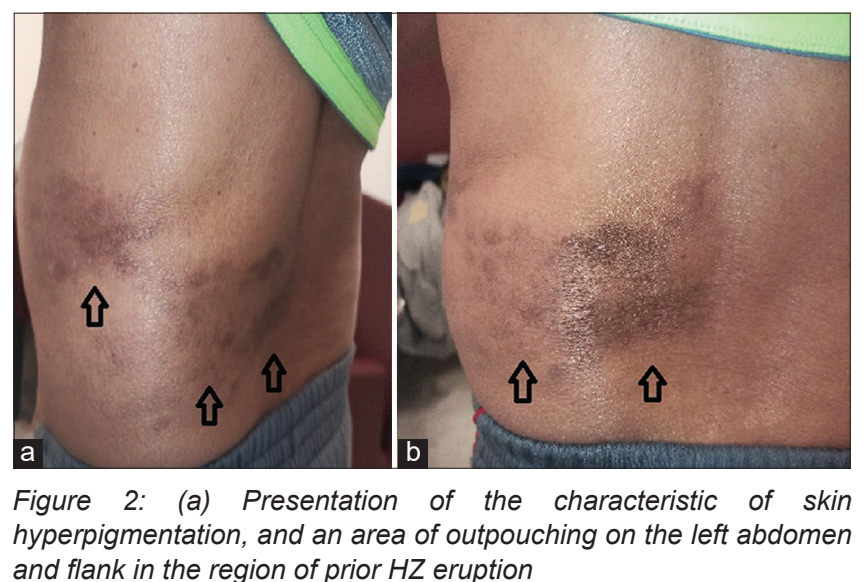

In the study group, 37 patients with postherpetic neuralgia after $\mathrm{HZ}$ infection had significantly higher medians of age ( $p<0.001)$, duration of $H Z$ infection $(p<0.001)$, VAS-baseline $(p<0.001)$, LANSS-baseline $(p<0.001)$ than those without postherpetic neuralgia. In patients with postherpetic neuralgia, the frequency of comorbidity ( $p<0.001)$, the frequency of prodromal findings ( $p<0.001)$, and the frequency of receiving medical treatment $(p=0.002)$ were statistically significantly higher. 
Table 1: Descriptive characteristics of the study group

\begin{tabular}{|c|c|}
\hline Age, Mean \pm SD, Median (Min-Max) & $50.8 \pm 19.2,48.5(5.0-88.0)$ \\
\hline Prodromal Duration of $\mathrm{HZ}$ infection (day), & $5.8 \pm 5.5,3.0(1.0-25.0)$ \\
\hline \multicolumn{2}{|l|}{ Mean \pm SD, Median (Min-Max) } \\
\hline \multicolumn{2}{|l|}{ (Min-Max) } \\
\hline LANSS-Baseline,Mean \pm SD, Median & $14.1 \pm 10.4,18.0(0.0-24.0)$ \\
\hline \multicolumn{2}{|l|}{ (Min-Max) } \\
\hline \multicolumn{2}{|l|}{ Age groups, n (\%) } \\
\hline$<18$ & $4(2.4)$ \\
\hline$\geq 18$ & $166(97.6)$ \\
\hline \multicolumn{2}{|l|}{ Gender, n (\%) } \\
\hline Male & $76(44.7)$ \\
\hline Female & $94(55.3)$ \\
\hline \multicolumn{2}{|l|}{ Treatment method, n (\%) } \\
\hline Topical & $29(17.1)$ \\
\hline Medical & $141(82.9)$ \\
\hline \multicolumn{2}{|l|}{ Prodromal sign, n (\%) } \\
\hline Absent & $53(31.2)$ \\
\hline Present & $117(68.8)$ \\
\hline \multicolumn{2}{|l|}{ Post-infectious skin sequelae, $n(\%)$} \\
\hline Absent & $125(73.5)$ \\
\hline Present & $45(26.5)$ \\
\hline \multicolumn{2}{|l|}{ Postherpetic neuralgia, n (\%) } \\
\hline Absent & $133(78.2)$ \\
\hline Present & $37(21.8)$ \\
\hline \multicolumn{2}{|l|}{ Comorbidity, n (\%) } \\
\hline Absent & $76(44.7)$ \\
\hline Present & 94 (55.3) \\
\hline Hypertension & $20(11.8)$ \\
\hline Diabetes mellitus & $18(10.6)$ \\
\hline Cardiovascular disease & $17(10.0)$ \\
\hline Malignancy & $7(4.1)$ \\
\hline HIV & $1(0.6)$ \\
\hline Pregnancy & $1(0.6)$ \\
\hline Other & $30(17.6)$ \\
\hline
\end{tabular}

The distribution of $\mathrm{HZ}$ dermatome outside the cervical region was found to be significantly different in patients with and without postherpetic neuralgia $(p=$ 0.005), (Table 2).

Table 2: Comparison of patients with and without postherpetic neuralgia in terms of characteristics after $\mathrm{HZ}$ infection

\begin{tabular}{|c|c|c|c|}
\hline & \multicolumn{2}{|c|}{ Postherpetic neuralgia } & \multirow[t]{2}{*}{$p$} \\
\hline & Absent & Present & \\
\hline Age, median (min-max) & $44.0(5.0-88.0)$ & $70.0(43.0-84.0)$ & $<0.001$ \\
\hline $\begin{array}{l}\text { Duration of HZ infection (day), median } \\
\text { (min-max) }\end{array}$ & $3.0(1.0-22.0)$ & $15.0(1.0-25.0)$ & $<0.001$ \\
\hline VAS-baseline,median (min-max) & $7.0(0.0-10.0)$ & $9.0(7.0-10.0)$ & $<0.001$ \\
\hline LANSS-baseline,median (min-max) & $10.0(0.0-24.0)$ & $24.0(10.0-24.0)$ & $<0.001$ \\
\hline \multicolumn{4}{|l|}{ Age groups, $n(\%)$} \\
\hline$<18$ & $4(3.0)$ & $0(0.0)$ & \multirow[t]{2}{*}{0.286} \\
\hline$\geq 18$ & $129(97.0)$ & $37(100.0)$ & \\
\hline \multicolumn{4}{|l|}{ Gender, n (\%) } \\
\hline Male & $56(42.1)$ & $20(54.1)$ & \multirow[t]{2}{*}{0.196} \\
\hline Female & 77 (57.9) & $17(45.9)$ & \\
\hline \multicolumn{4}{|l|}{ Comorbidity, n (\%) } \\
\hline Absent & $74(55.6)$ & $2(5.4)$ & \multirow{2}{*}{$<0.001$} \\
\hline Present & $59(44.4)$ & $35(94.6)$ & \\
\hline \multicolumn{4}{|l|}{ Prodromal sign, n (\%) } \\
\hline Absent & $53(39.8)$ & $0(0.0)$ & \multirow[t]{2}{*}{$<0.001$} \\
\hline Present & $80(60.2)$ & $37(100.0)$ & \\
\hline \multicolumn{4}{|l|}{ Treatment method, n(\%) } \\
\hline Topical & $29(21.8)$ & $0(0.0)$ & \multirow[t]{2}{*}{0.002} \\
\hline Medical & $104(78.2)$ & $37(100.0)$ & \\
\hline \multicolumn{4}{|l|}{ Dermatome, n (\%) } \\
\hline Cranial region & $19(14.3)$ & $2(5.4)$ & \multirow[t]{5}{*}{0.005} \\
\hline Lumbar region & $27(20.3)$ & $12(32.4)$ & \\
\hline Sacral region & $26(19.5)$ & $2(5.4)$ & \\
\hline Cervical region* & $8(6.0)$ & $8(21.6)$ & \\
\hline Thoracic region & $53(39.8)$ & $13(35.1)$ & \\
\hline
\end{tabular}

\section{Discussion}

Herpes zoster is caused by the reactivation of the varicella-zoster virus. Unlike chickenpox, the lifetime estimated incidence of herpes zoster ranges from about $10-20 \%$. The incidence of herpes zoster increases sharply with advancing age, roughly doubling every decade beyond the age of 50 . In a previous study, 1 patient over the age of 55 accounted for over $30 \%$ of herpes zoster cases, although they only represented 8 percent of the study population. In the same study, children younger than 14 years old represented only 5 percent of herpes zoster cases [2], [8] Our results support a number of earlier studies, but the in our study $\mathrm{HZ}$ incidence found higher $21.8 \%(n=37)$, which reported in other studies age was as a risk indicator of PHN. We thought our high rate was due to our average age (50.8 $\pm 19.2)$ and high rate of comorbidity $55.3 \%(n=94)$. This higher risk of developing PHN with increasing age has often been explained by the decreasing immunity seen in older people. In addition, our absence of findings on $\mathrm{PHN}$ in patients under 18 years of age $(n=4)$ confirms the results of a study conducted on $\mathrm{HZ}$ in Iceland in children and adolescents [9] and shows that the risk of developing $\mathrm{PNH}$ increases with age.

One possible risk factor for $\mathrm{HZ}$ is exposure to ultraviolet radiation (UVR) from sunlight as it can suppress the cell-mediated immune response. Several observations support this hypothesis. The risk of $\mathrm{HZ}$ is higher in the summer than other seasons, possibly due to high UVR exposure. Especially in this literature, this rate was found to be higher in men [10]. Considering that the northern Cyprus region is sunny and hot for approximately 300 days, it was also an additional risk factor for our patients.

$\mathrm{HZ}$ disease has prodromal symptoms before the lesion develops. these; it includes symptoms such as allodynia, pain, itching, and burning. Some patients have these symptoms without a rash, also known as "zoster sinus herpes" [11].

Symptoms typically include prodromal sensory phenomena during 1 or more skin dermatomes lasting 1-10 days (average $48 \mathrm{~h}$ ). In a study investigating the prodromal pain and severity of $\mathrm{HZ}$, the prodromal symptom rate was found to be $74 \%$ [12]. In our study we found that a painful prodrome in our patient was $68.8 \%$ $(n=117)$, which could be considered a sign of more severe $\mathrm{HZ}$, was associated with an increased risk of $\mathrm{PHN}$. In the same study prodromal pain was associated with more severe acute pain (Initial Zoster Impact Questionnaire. 6.2 vs. 4.3, p- 0.0001). Similar with these results our patients with postherpetic neuralgia after $\mathrm{HZ}$ infection had significantly higher medians VAS-baseline $(p<0.001)$, LANSS-baseline $(p<0.001)$ than those without postherpetic neuralgia.

The dermatomal distribution of $\mathrm{HZ}$ in this study is shown in Table 2 and is comparable to other studies [13], [14]. These studies reported an involvement of thoracic dermatomes $(44 \%-56.4 \%)$, trigeminal dermatomes $(11.8 \%-25 \%)$, cervical dermatomes $(11 \%-20 \%)$, and lumbosacral dermatomes $(11 \%-17 \%)$. $\mathrm{PNH}$ developed in all dermatomes except cervical involvement in our patients. 
Skin damaged primarily by viruses may be susceptible to a secondary skin lesion. Skin physically deformed by the previous disease may be a result of the response. In contrast, skin scars are not often reported after herpes zoster $(\mathrm{HZ})$. Risk factors for post-HZ scarring remain undetermined. In a study investigating the incidence and risk factors of cutaneous scars after herpes zoster, it was reported that $11(9.7 \%)$ of 113 patients developed postinflammatory scar (hypo/ hyperpigmentation, atrophy, keloid) in a 6-month follow-up. Immunosuppression and severe herpes zoster were identified as risk factors [15]. In our study the frequency of post-infective sequelae (atrophy, hypo/ hyperpigmentation) among the patients was found to be $26.5 \%(n=45)$, This risk was too high in patients with malignancies, weak immune system, and severe widespread rash.

Current treatment of $\mathrm{HZ}$ with antiviral drugs and analgesics gives good results in younger patients where the disease is generally milder and is effective against acute pain and skin rashes. However, it is much less effective against PHN, which occurs more frequently and more severely in elderly patients. Once PHN develops, current treatments offer only limited benefits and side effects need to be reviewed [16].

Ideal treatment for herpes zoster should be initiated within $72 \mathrm{~h}$ after the rash appears, but if new skin lesions are developing or ophthalmic or neurological complications are present, this treatment can be applied outside the 72-h window [17].

The standard treatment is acyclovir $(800 \mathrm{mg}$ 5 times a day). If the disease is severe, the intravenous application is warranted [18] Valaciclovir (1000 mg) and famciclovir $(500 \mathrm{mg}$ ) can be given 3 times a day. These agents are as effective as acyclovir possibly due to better absorption and higher blood levels. In recent studies, valaciclovir, $1.5 \mathrm{~g}$ orally twice daily, was found to accelerate the resolution of the $\mathrm{HZ}$ rash, associated pain, and reduce the duration of $\mathrm{PHN}$ in immunosuppressed patients [19].

Controversial a study conducted by Alakloby et al. In Eastern Arabia there was no significant difference between patients with $\mathrm{PHN}$ who received systemic acyclovir and those who did not receive it. Likewise, no significant difference was observed in the disease duration between patients who used systemic treatment and those who did not use it [20]. Based on the previous literature, there are no data on the development of PHN in patients receiving topical antiviral therapy [18]. In contrast to this result, in our study patient, those who received topical treatment had a lower risk of developing $\mathrm{PNH}$. In addition, $\mathrm{PNH}$ was developed in 37 of 141 patients who received systemic therapy. Frequency of receiving medical treatment $(p=0.002)$ was significantly higher in the PNH group. Management approaches include treatment of herpes zoster infection and associated pain, prevention of postherpetic neuralgia, and control of neuropathic pain until the condition is resolved.

\section{Conclusion}

As a result, the incidence of herpes zoster is increasing every year due to the increasing life expectancy and the addition of various comorbid diseases. Unfortunately, this situation puts a serious burden on the health system. Based on these studies, we have compiled 170 patients with herpes zoster in our hospital. Females were more affected than males. The thoracic dermatomes were the most commonly involved. The most common coexisting disease was hypertension, diabetes mellitus, and the most common complication of $\mathrm{HZ}$ was $\mathrm{PHN}$. Prevention strategies, such as vaccinating those at greatest risk, can offer the best option for the future.

\section{Ethical approval}

committee.

Approval was provided by local ethics

\section{References}

1. Nair PA, Patel BC. Herpes zoster. In: Stat Pearls. Treasure Island, FL: Stat Pearls Publishing; 2020.

2. Donahue JG, Choo PW, Manson JE, Platt R. The incidence of herpes zoster. Arch Intern Med. 1995;155(15):1605-9. https:// doi.org/10.1001/archinte.1995.00430150071008

PMıd:7618983

3. GauthierA,BreuerJ, CarringtonD, MartinM,RemyV.Epidemiology and cost of herpes zoster and post-herpetic neuralgia in the United Kingdom. Epidemiol Infect. 2009;137(1):38-47. https:// doi.org/10.1017/s0950268808000678

PMıd:18466661

4. Nalamachu S, Morley-Forster P. Diagnosing and managing postherpetic neuralgia. Drugs Aging. 2012;29(11):863-9. https:// doi.org/10.1007/s40266-012-0014-3

PMıd:23038608

5. Mallick-Searle T, Snodgrass B, Brant JM. Postherpetic neuralgia: Epidemiology, pathophysiology, and pain management pharmacology. J Multidiscip Healthc. 2016;9:447-54. https://doi. org/10.2147/jmdh.s106340

PMıd:27703368

6. Dubinsky RM, Kabbani H, El-Chami Z, Boutwell C, Ali H, Quality Standards Subcommittee of the American Academy of Neurology. Practice parameter: Treatment of postherpetic neuralgia: An evidence-based report of the quality standards subcommittee of the American Academy of Neurology. Neurology. 2004;63(6):959-65. https://doi.org/10.1212/01. wnl.0000140708.62856.72

PMıd:15452284

7. Argoff CE. Review of current guidelines on the care of postherpetic neuralgia. Postgrad Med. 2011;123(5):134-42.

PMıd:21904096 
8. Hope-Simpson RE. Postherpetic neuralgia. J R Coll Gen Pract. 1975;25(157):571-5.

\section{PMıd:1195231}

9. Petursson G, Helgason $S$, Gudmundsson $S$, Sigurdsson JA. Herpes zoster in children and adolescents. Pediatr Infect Dis J. 1998;17(10):905-8. https://doi. org/10.1097/00006454-199810000-00011 PMıd:9802633

10. Zak-Prelich M, Borkowski JL, Alexander F, Norval M. The role of solar ultraviolet irradiation in zoster. Epidemiol Infect. 2002;129(3):593-7. https://doi.org/10.1017/ s0950268802007793

PMıd:12558343

11. Oxman MN. Clinical manifestations of herpes zoster. In: Arvin AM, Gershon AA, editors. Varicella-Zoster Virus: Virology and Clinical Management. Cambridge, England: Cambridge University Press; 2000. p. 246-75. https://doi.org/10.1017/ cbo9780511601194.015

12. Benbernou A, Drolet M, Levin MJ, Schmader KE, Oxman MN, Johnson $\mathrm{R}$, et al. Association between prodromal pain and the severity of acute herpes zoster and utilization of health care resources. Eur J Pain. 2011;15(10):1100-6. https://doi. org/10.1016/j.ejpain.2011.04.014 PMıd:21600819

13. Choo PW, Galil K, Donahue JG, Walker AM, Spiegelman D, Platt R. Risk factors for postherpetic neuralgia. Arch Intern Med. 1997;157(11):1217-24. https://doi.org/10.1001/ archinte.1997.00440320117011

PMıd:9183233

14. Arvin AM. Varicella-zoster virus. Clin Microbiol Rev. 1996;9(3):361-81.

PMıd:8809466
15. El Hayderi L, Nikkels-Tassoudji N, Nikkels AF. Incidence of and risk factors for cutaneous scarring after herpes zoster. Am J Clin Dermatol. 2018;19(6):893-7. https://doi.org/10.1007/ s40257-018-0385-2

PMıd:30151702

16. Johnson RW. Herpes zoster and postherpetic neuralgia. Expert Rev Vaccines. 2010;9 Suppl 3:21-6. https://doi.org/10.1586/ erv. 10.30

PMıd:20192714

17. Cohen Jl. Clinical practice: Herpes zoster. N Engl J Med 2013;369(3):255-63. PMıd:23863052

18. Werner RN, Nikkels AF, Marinović B, Schäfer M, CzarneckaOperacz M, Agius AM, et al. European consensus-based (S2k) guideline on the management of herpes zoster-guided by the European Dermatology Forum (EDF) in cooperation with the european academy of dermatology and venereology (EADV), Part 2: Treatment. J Eur Acad Dermatol Venereol. 2017;31(1):20-9. https://doi.org/10.1111/jdv.13957 PMıd:27579792

19. Madkan VK, Arora A, Babb-Tarbox M, Aboutlabeti S, Tyring S Open-label study ofvalacyclovir $1.5 \mathrm{~g}$ twice daily for the treatment of uncomplicatedherpes zoster in immunocompetent patients 18 years of age orolder. J Cutan Med Surg. 2007;11(3):89-98. https://doi.org/10.2310/7750.2007.00016

PMıd:17511925

20. Alakloby OM, AlJabre SH, Randhawa MA, Alzahrani AJ AlWunais KM, Bukhari IA. Herpes zoster in eastern Saudi Arabia: Clinical presentation and management. J Drugs Dermatol. 2008;7(5):457-62.

PMıd:18505138 